\title{
nature
}

NATURE VOL. 32519 FEBRUARY 1987

\section{AIDS and illiberal measures tinnarax}

\section{Personal liberty should be protected in the battle against AIDS but not at all costs. Registration of infected individuals makes little sense but the testing of anonymous blood samples should proceed.}

\begin{abstract}
IT was always on the cards that panic about the spread of AIDS (acquired immune deficiency syndrome) would engender illiberal adaptations of social principles long regarded as essential safeguards of personal liberty. As long as there is neither cure nor prophylactic for the disease, and while it remains possible that all those who become infected will eventually die (it is too soon to know what the proportions are), people are right to be alarmed that whole populations are at risk. The questions that arise are those familiar during wars: what restrictions of liberty are necessary to win and at what point, along that road, does illiberality make victory hollow?
\end{abstract}

Governments' first reactions (most creditable, so far, in Britain) have rightly been that public education must be the first line of defence. The obvious difficulty is that there is no record of success in changing people's sexual habits by exhortation and every reason to fear that the social groups that are both most vulnerable and most effective as agents of the spread of infection (young people chief among them) will be immune from persuasion. Another is that the sexual explicitness essential if public education is to be effective is itself socially disturbing. Already, in the United States, the Public Health Service and the Department of Education have been at odds (Nature 325, 287; 1987), while church groups in North America and Western Europe, including those that have made chastity a profession, are predictably beginning to dig in their heels. So people are beginning to cast around for other things to do.

The proposition that found its way onto last November's ballot in California (and which was thrown out) would simply have required that the condition of those known to be infected with the AIDS virus should be publicly registered as such. During the past weeks, similar ideas have been widely canvassed in West Germany (see page 650). On the face of things, they have a beguiling logic. If the threat to society is as serious as it could be, would it not make sense that those capable of transmitting the disease should in principle be identifiable and thus avoidable by those, for example, who might be about to go to bed with them? Unfortunately for the logic, there is not much chance that intending partners overtaken by sexual emergency would be diligent at consulting public registers, which would instead be used for other purposes, not all of them socially benign. The only enduring consequence of registration would be general ostracism of the infected, the principle of the old leper colonies. Would it make sense to make such a big leap backwards when other more seemly remedies are not exhausted?

There is, moreover, no good reason for believing that AIDS registration would be useful for any of the practical purposes for which it is at present canvassed. The claim that registration, even if it were only to take the form of a card carried by each individual proving that he or she had been tested for AIDS, would enable those at risk to avoid dangerous sexual partners, is largely denied by the circumstances of the case. The only tests for AIDS at present widely applicable are tests for antibody to the virus, which makes its appearance only some time after infection, perhaps a few months on the average.

None of this is an argument against testing. Especially as programmes of public education take hold in people's minds, those who think they have been running risk will look for means of telling what the truth is. They will discover that reassurance is hard to come by. Testing facilities are mostly inadequate. Moreover, as the old-fashioned venereal-disease clinics know too well, there are awesome problems of confidentiality. Obviously the person who seeks testing must be told the result, but should the testers also have powers to trace and find all sexual contacts? On the face of things, the universal adoption of such a policy would make good sense. But there are horrendous difficulties. First, there is the obvious problem that those at risk are less likely to offer themselves for testing if they know their contacts will be traced. Then there is the difficulty of.conducting an investigation of a person's life without casting a slur over all those concerned. There is also the problem that the tracing and testing of all sexual contacts of an infected person is expensive both of people's time and of money, especially if it is accompanied by proper attention to the counselling of those concerned. At some stage in this battle, it may seem that the compulsory tracing of the sexual contacts of infected people would be worthwhile; but nobody should expect too much of it. Meanwhile, a more subtle moral issue has arisen, both in Britain and the United States (where public health authorities have been beating their breasts on the subject for the past few weeks). The question is whether it can ever be proper to attempt to estimate the incidence of infection in the population at large, a number crucial to serious attempts to chart the future of the disease, by the anonymous testing of blood taken from patients for quite different purposes. A group of physicians in Britain has been asking for months for this course to be followed with blood sampled during pregnancies.

Anonymous testing would at present be disallowed because it violates the cornerstone of codes of ethics which lay down that people should be asked to give their consent to what is intended. Another ethical objection to the procedure is that the anonymous people who were found to be infected could not be given this information, even if they would find it valuable. These are issues on which governments and professional bodies should be prepared to bend the present rules. Nobody whose blood was tested anonymously would be the worse off, whatever the result of the test. Moreover, the data that could come from testing of this kind would be an invaluable means of monitoring the progress of the disease. If the battle against AIDS were a real war, there would be no doubt of what should be done. \section{Where to go next? dimadiox} The House of Lords has told more truth than most on UK science: now it has another chance. Is the quality of research too important to be left to politicians and civil servants? And is the dreadful condition into which the British research enterprise has been driven in the past seven years the result of the way in which government departments have been free to do what seems to them to be sensible, unhindered by protests from people in a position to know what damage their decisions would cause? These are the sceptical ques- 